\title{
İstanbul İli Anadolu Yakası Doğal Kaynak Sularının Kimyasal Analizlerinin Değerlendirilmesi
}

\author{
Selin GÜLTEKIN ${ }^{*}$, Cenk SESAL ${ }^{2}$, Figen Esin KAYHAN ${ }^{2}$ \\ ${ }^{1}$ IBB (İstanbul Büyük Şehir Belediyesi) Sağlık ve Sosyal Hizmetler Daire Başkanlığl, Sağllk ve Hıfzlssıhha Müdürlüğ̈̈, \\ Atatürk Bulvarl, Vefa Sokak No:16, 34130 Saraçhane Fatih, İstanbul \\ ${ }^{2}$ Marmara Üniversitesi, Fen Edebiyat Fakültesi, Biyoloji Bölümü, Göztepe Kampüsü, 34722 Göztepe, İstanbul
}

\section{ÖZET}

Su yaşamın vazgeçilmezidir. İçme sularının, hastalık ve zararlı etki yapabilecek mikroorganizmalar ile mineral ve organik maddelerden arındırılmış olması gerekmektedir. Küresel iklim değişiklikleri, sanayileşme ve hızlı nüfus artışına bağlı olarak gittikçe kirlenen mevcut su kaynakları insanları içme, kullanma ve sulama amaçları doğrultusunda yeraltı suların korumaya ve doğru kullanmaya yönlendirmiştir. Bu çalışmada İstanbul ili Anadolu yakasında bulunan değişik yerleşim alanlarından farklı bölgeleri temsil niteliği taşıyabilecek 10 adet kaynak suyu çeşmesi belirlenmiştir. Bu kaynak suyu çeşmelerinden bir y1llık süreçte (2014 yılı /12 ay) temin edilen 95 örneğin kimyasal analizleri yapılmıştır. Analizler neticesinde 26 örneğe ait $\mathrm{pH}$ değerleri ulusal ve uluslararası standartlara, 92 örneğin serbest klor değerleri ise sadece İnsani Tüketim Amaçlı Sular Hakkındaki Yönetmeliğe aykırı olarak tespit edilmiştir. Çalışmamız neticesinde kaynak sularımızın iletkenlik, amonyum, nitrit, klorür, toplam sertlik, florür ve kalsiyum değerlerinin ulusal ve uluslararası standartlara uygun olduğu belirlenmiştir.

Anahtar Kelimeler: Doğal kaynak suyu, Su kalitesi, Kimyasal parametreler, Sularda Kirlilik kaynakları, İklim

\section{Chemical Analysis Evalution of Natural Spring Water in Anatolian Side of Istanbul Province}

\begin{abstract}
Water is essential for life. The drinking waters must be purify from microorganisms, minerals and organic substances which cause diseases and harmful effects. Depending on global climate changes, industrialization and rapid population growth, increasingly polluted existing water resources have led to people to protect and use right for drinking, usage and irrigation purposes .In this study, 10 spring water fountains which could illustrate different regions from various residental areas in Istanbul's Anatolian side has been identified. 95 samples which have been obatined from this spring water fountains in one year period (2014 year/12 month), were performed chemical analyzes. In the end of the analyzes, while ph values of the 26 samples against to national and international standards have been determined, free chlorine values of the 92 samples aganist to only regulation concerning water intended for human consumption have been determined. As a result of our work, conductivity, ammonia, nitrite, chloride, total hardness, fluoride and calcium values of our water resources were determined for compliance according to national and international standarts.
\end{abstract}

Keywords: Natural spring water, Water quality, Chemical parameters, Sources Of Wate Pollution, Climate 


\section{Giriş}

Dünya yüzeyinin dörtte üçü sularla kaplı olmasına rağmen, insan kullanımına uygun tatlı su miktarı oldukça kısıtlıdır. Dünya üstündeki toplam tatlı su miktarı yaklaşık dünya üzerindeki toplam suyun $\% 2,5^{\prime}$ i olup bunun yalnızca $\% 0,3$ 'ü ekosistem ve insan kullanımına elverişli tatlı su kaynaklarından oluşmaktadır. Geri kalan tatlı sular çoğunlukla buzullarda ve yeraltı rezervlerinde hapsolmuştur [1]. Küresel olarak Dünya su kaynaklarının yaklaşık \%70'i tarım amaçlı kullanılmaktadır. Bunu \%19 ve \%11 ile sanayi ve evsel kullanım izlemektedir [2]. Evsel su tüketimi yerel kullanılabilir su mevcudiyeti ve nüfusun büyüklügüne son derece bağımlıdır [3]. Kullanıma uygunluğu ve talebi arasındaki dengesizlikler, yer altı ve yerüstü su kalitesinin bozulması, sektörler arası rekabet, bölgeler arası ve uluslararası ihtilaflar su sorununu ön plana çıkarmaktadır [4]. Su kıtlı̆̆ı gelecekte en önemli problemlerden biri olacaktır. Geçtiğimiz 50 yılda, su kaynaklarının miktarı aynı kalmasına rağmen, su çekimi üç katına çıkmıştır [5]. Kişi başına günlük ortalama kentsel su tüketim standardı; Türkiye'de 111 litre olup, dünya ortalaması 150 litredir. Sağlıklı suya erişen nüfusun toplam nüfusa oranının dünya ortalaması $\% 82$ olup, Türkiye'de bu oran $\% 93$ 'tür [6].

Dünya nüfusunun çok hızlı artışı, sanayi ve teknolojinin aşırı gelişmesi, çevre bilincinin yeterince yaygınlaşamaması gibi nedenler dünyada içilebilir su miktarının giderek azalmasına neden olmaktadır. Ayrıca içilebilir su kaynaklarının sorumsuzca kirletilmesi, geri dönüşümü imkânsız sorunların vuku bulmasına ortam hazırlamaktadır. Tahminlere göre, artan su ihtiyacı ile giderek azalan temiz su kaynağı eğrileri 2030 yılında kesişecektir. Bu durum doğal olarak evrensel bir kriz olacağını akıllara getirmektedir [7]. İnsanların sağlıklı yaşamaları için gerekli olan suyun kullanılabilmesi için fiziksel, kimyasal ve bakteriyolojik açıdan, kullanım amaçlarına uygunluğunun belirlenmesi ve belli sınırları aşmaması, özellikle içme sularının hastalık ve zararlı etki yapabilecek mikroorganizmalar ile mineral ve organik maddelerden arındırılmış olması gerekmektedir. Günümüzde küresel iklim değişikliği, sanayileşme ve hızlı nüfus artışına bağlı olarak gittikçe kirlenen mevcut su kaynakları insanları içme, kullanma ve sulama amaçları doğrultusunda yeraltı sularını korumaya ve doğru kullanmaya yönlendirmiştir [8]. Suyun fiziksel ve kimyasal aç1dan değerlendirilmesi su kalitesinin belirlenmesi açısından oldukça önemlidir. Bölge halkı tarafından sıklıkla kullanılan sokak çeşmelerinin halk sağlığı açısından sürekli olarak incelenmesi gerekmektedir. Bu çalışmanın amacı, İstanbul İli Anadolu yakasında belirlenen on adet doğal içme suyu kaynağının kimyasal yönden analizlerini değerlendirmek ve uygunluğunu tespit etmektir.

\section{Materyal ve Yöntem}

İstanbul ili Anadolu yakasında bulunan değişik yerleşim alanlarından farklı bölgeleri temsil niteliği taşıyan 10 adet kaynak suyu çeşmesi belirlenerek (bunlar S1-S10 olarak tanımlanmıştır), bir yıl süreyle (Ocak - Aralık 2014) her ay kimyasal analizler için numuneler alındı. Belirlediğimiz kaynak suyu çeşmeleri ve bulundukları bölgeler Tablo 1'de verildiği gibidir. Ayrıca bu kaynak suyu çeşmelerinin harita üzerindeki lokasyonları Şekil 1'de gösterildi.

Tablo 1: Anadolu Yakası Kaynak Suyu Çeşmeleri ve Lokasyonlar1

\begin{tabular}{|c|l|l|}
\hline Numune & $\begin{array}{c}\text { Kaynak Suyu } \\
\text { Çeşmeler }\end{array}$ & \multicolumn{1}{|c|}{ Bulundukları Bölge } \\
\hline S1 & Başıüyük & Başıüyük Mahallesi (Maltepe) \\
\hline S2 & Ferah son çeşme & Büyük Çamlıca Mahallesi (Üsküdar) \\
\hline S3 & Göztepe & Göztepe Mahallesi (Kadıöy) \\
\hline S4 & Haminnine Suyu & Küçük Çamlıca Mahallesi (Üsküdar) \\
\hline S5 & İçerenköy & İçerenköy Mahallesi (Ataşehir) \\
\hline S6 & Kayışdağ & Kayışdağ Mahallesi (Ataşehir) \\
\hline S7 & Kozyatağ1 & Kozyatağ1 Mahallesi (Kadıöy) \\
\hline S8 & Sahrayıcedid & Sahrayıcedid Mahallesi (Kadıöy) \\
\hline S9 & Tatlı Su-1 & Esenkent Mahallesi (Maltepe) \\
\hline S10 & Tatlı Su-2 & Esenkent Mahallesi (Maltepe) \\
\hline
\end{tabular}

Numune alma teknikleri ile ilgili işlemler TS EN ISO 5667-1 [9], TS EN ISO 5667-3 [10], TS ISO 5667-5 [11], standartlarına göre yapıldı. Fiziksel ve kimyasal analizler için numune hacimleri ve uygun numune kapları, numunelerin korunması ve saklama yöntemi, numunelere daha sonra uygulanacak işlemler TS EN ISO 5667-3 [10], standardına göre uygulandi. Numunelerin fiziksel analiz olarak koku, bulanıklık, yabancı madde parametreleri organoleptik olarak değerlendirildi. Bu bağlamda çürük, yosun, küf, hidrojen sülfür, amonyak, bataklık kokusu gibi kokuların ve tortunun olup olmadığı TS 266 [12], standardında belirtilen, suların organoleptik özellik muayenesi kapsamında değerlendirildi.

Kaynak sularımızın kimyasal kalitelerinin belirlenmesinde ise serbest klor, $\mathrm{pH}$, iletkenlik, amonyum, nitrit, klorür, toplam sertlik, florür, kalsiyum parametrelerinin analizleri yapıldı. Numunelerimizin amonyum, nitrit, florür düzeyleri spektrofotometrik yöntem ile Hach DR/2500 Spektrofotometre cihazı kullanılarak belirlendi. Amonyum, Nessler Method yöntemine [13]; Nitrit, Diazotization Method LR yöntemine [14]; Florür ise SPADNS Method'a [15] uygun olarak yapıldı. Kalsiyum, toplam sertlik ve klorür düzeyleri ise titrimetrik yöntem ile belirlendi. Kalsiyum tayininde ise TS 8196 Edta Titrimetrik Metot [16], klorür tayininde; TS 4164 ISO 9297 Mohr Metodu [17] ve APHA, 4500-Cl- B standardı [18] kullanıldı. Serbest klor tayininde, DPD hazır 


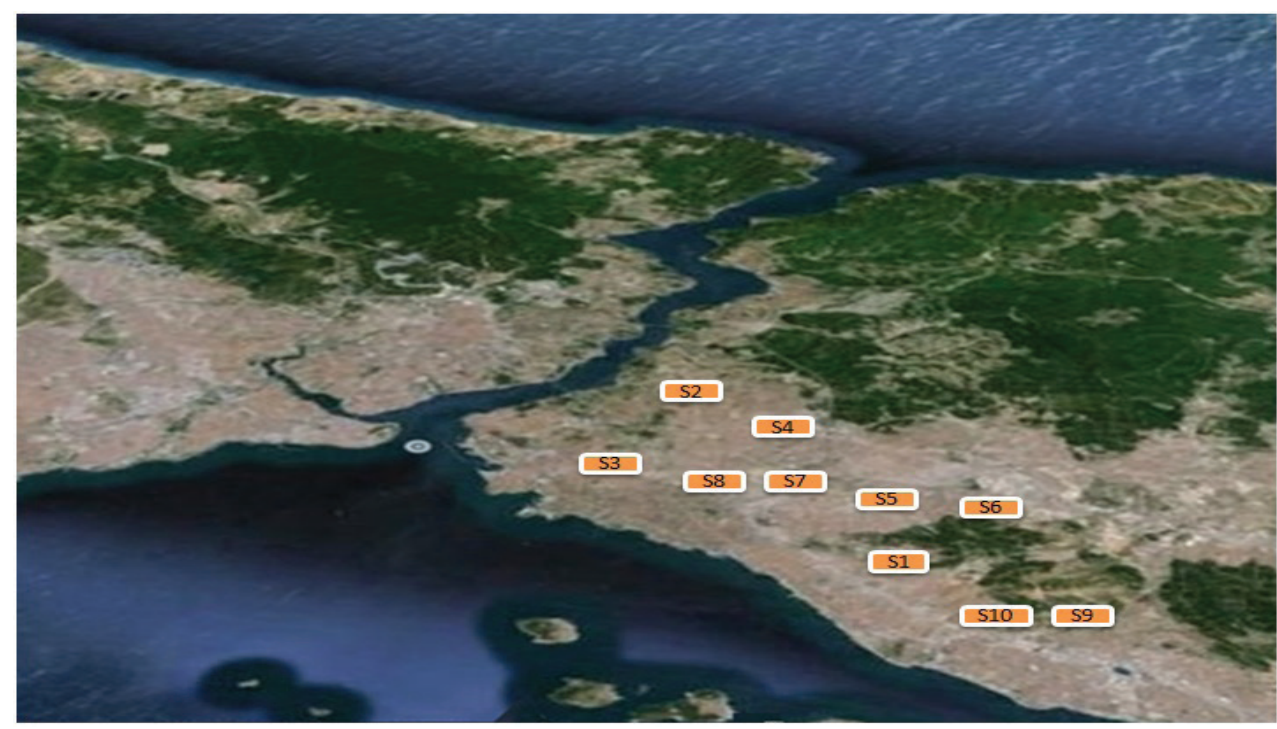

Şekil 1: Anadolu Yakası Kaynak Suyu Çeşmelerinin Harita üzerindeki Lokasyonları

kit metodu [19] kullanılarak, görsel kıyaslama ile kolorimetrik ölçüm yapıldı. pH tayini Mettler Toledo MP220/225 pH metre cihazı kullanılarak, TS EN ISO 10523 standardına [20] göre uyguland1. İletkenlik tayini WTW, İnolab (Cond Level- 1) İletkenlik Ölçüm Cihazı ile APHA, 2510-B standartına [21] uygun olarak yapıldı.

\section{Bulgular}

Dünya Sağlık Teşkilatı, ABD Çevre Koruma Ajansı, Avrupa Birliği, Türk Standartları Enstitüsü İçme Suyu Standardı ve
Sağlık Bakanlığı İnsani Tüketim Amaçlı Sular Hakkındaki Yönetmelik'te belirtilen kimyasal kalite parametreleri ve ilgili sınır değerleri Tablo 2'de gösterildi [22,23,24,12,25].

Kaynak suyu numunelerimizin tamamının organoleptik özellikler açısından kendine has kokuda, tüketicilere uygun bulanıklıkta, berrak, tortusuz olduğu ve yabancı madde bulunmadığı tespit edildi. Bu sonuçlar, TS 266 standardındaki "organoleptik özellikleri açısından su; berrak, tortusuz, kendine has renkte ve kokusuz olmalıdır." ifadesine uygunluk arz etmektedir [12].

Tablo 2: İçme Sularının Kimyasal Kalite İçin Genel Parametreleri

\begin{tabular}{|c|c|c|c|c|c|}
\hline & $\begin{array}{c}\text { İNSANI TÜKETIM } \\
\text { AMAÇLI SULAR } \\
\text { HAKKINDAKİ } \\
\text { YÖNETMELIK }\end{array}$ & $\begin{array}{l}\text { TS } 266 \\
(2005)\end{array}$ & $\begin{array}{c}\text { DÜNYA SAĞLIK } \\
\text { TEŞKİLATI } \\
\text { (WHO, 2011) }\end{array}$ & $\begin{array}{l}\text { ABD ÇEVRE KO- } \\
\text { RUMA AJANSI } \\
\text { (EPA, 2008) }\end{array}$ & $\begin{array}{c}\text { AVRUPA } \\
\text { BİRLÍĞİ } \\
(\mathrm{EC}, 1998)\end{array}$ \\
\hline Serbest Klor (mg/L) & $0,2-0,5$ & - & 5 & 4 & - \\
\hline pH & $6,5-9,5$ & $6,5-9,5$ & $6,5-8$ & $6,5-8,5$ & $6,5-9,5$ \\
\hline İletkenlik $(\mu \mathrm{S} / \mathrm{cm})$ & 2500 & 2500 & - & - & - \\
\hline Amonyum (mg/L) & 0,5 & 0,5 & 1,5 & - & 0,5 \\
\hline Nitrit (mg/L) & 0,5 & - & - & - & - \\
\hline Klorür (mg/L) & 250 & 250 & 250 & 250 & 250 \\
\hline Toplam sertlik (mg/L) & - & - & 500 & - & - \\
\hline Florür (mg/L) & 1,5 & 1,5 & 1,5 & 2 & 1,5 \\
\hline Kalsiyum (mg/L) & - & 200 & 300 & - & 100 \\
\hline
\end{tabular}


Doğal kaynak içme suyu çeşmelerinden alınan su numunelerinde yapılan analizler sonucunda elde ettiğimiz kimyasal parametre bulguları Tablo 3 'te belirtildi. Buna göre kaynak suyu numunelerinde bir yıllık süreçte, $\mathrm{pH}$ '1n 5,8 - 7,6; iletkenliğin 71,8 - $427 \mu \mathrm{S} / \mathrm{cm}$; klorür'ün 15,9 - 78,1 mg/L; toplam sertliğin $1,8-13,4^{0} \mathrm{~F}$; florür'ün $0-0,46 \mathrm{mg} / \mathrm{L}$; kalsiyum'un 4,7 - 40,5 mg/L değerleri arasında değiştiği görüldü. Tespit edilen en yüksek değerler ise $\mathrm{pH}$ için; $\mathrm{S} 3$ ve $\mathrm{S} 8$ çeşmelerinde şubat ve mart aylarında, iletkenlik için ağustos ayında S9 çeşmesinde, klorür için yılın ilk sekiz aylık döneminde S9 çeşmesinde, toplam sertlik için aralık ayında S9 çeşmesinde, florür için aralık ayında S5 çeşmesinde, kalsiyum için ise kasım ayında S9 çeşmesinde tespit edildi. Kaynak suyu numunelerinin hiçbirinde amonyum ve nitrit tespit edilmedi.
Kaynak sularına ait kimyasal ve fiziksel parametreler üzerine kuraklığın etkileri incelenirken daha önceki dönemleri kapsayan hidrolojik kuraklık bulguları da değerlendirildi. Bu bağlamda Şekil 2'de doğal kaynak sularının bulunduğu lokasyonlara ait 5 yıllık kuraklık analizi gösterildi. Meteoroloji Genel Müdürlüğü verilerine göre, kaynak sularımızın bulunduğu bölgelere ait 12 aylık (Ocak 2014-Aralık 2014) kuraklık analizine göre kuraklık durumu normal civarıdır. Aralık ayı yağışı 58 mm'dir. Önceki yıl aynı dönemin kuraklık durumu olağanüstü kurak, en kurak 12 aylık dönem 2013 yılı olağanüstü kurak olarak tespit edilmiştir. Daha önceki 24 aylık dönemin kuraklık analizine bakıldığında orta derecede kurak olduğu görülmektedir [26].

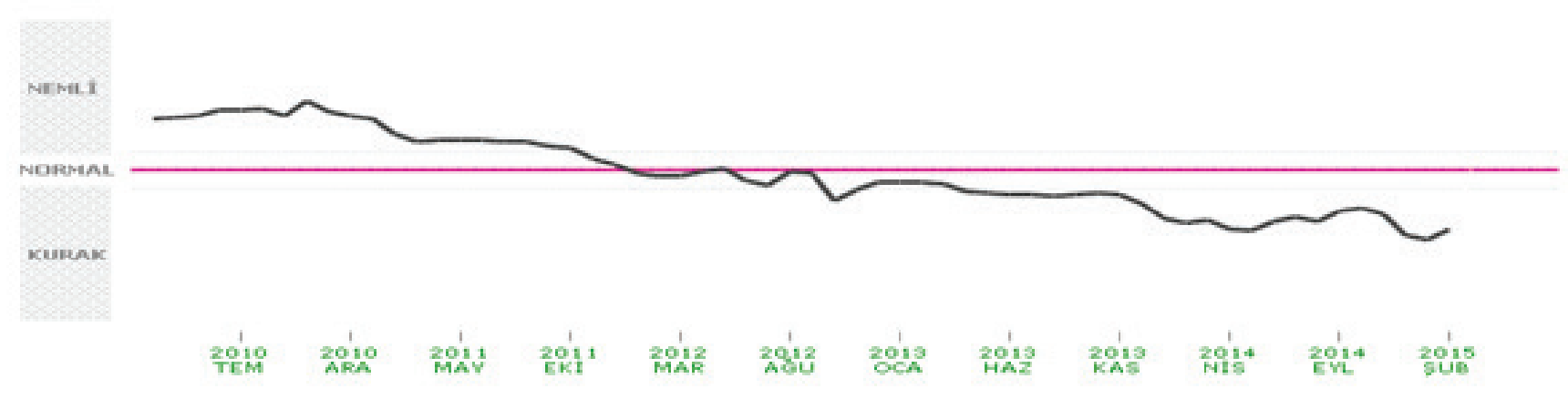

Şekil 2: Doğal Kaynak Sularının Bulunduğu Lokasyonlara ait 5 Yıllık Kuraklık Analizi

Tablo 3: Kaynak Suları Çeşmelerinden Ocak-Aralık 2014 Ayları Arasında Elde Edilen Kimyasal Analiz Sonuçları

\begin{tabular}{|c|c|c|c|c|c|c|c|c|c|c|c|c|c|}
\hline BAȘIBÜYÜK & BİRIM & OCAK & ŞUBAT & MART & NISAN & MAYIS & HAZIRAN & TEMMUZ & AĞUSTOS & EYLÜL & EKİM & KASIM & ARALIK \\
\hline SERBEST KLOR & $\mathrm{mg} / \mathrm{L}$ & 0 & 0 & 0 & 0 & - & - & 0 & - & - & - & - & 0 \\
\hline $\mathrm{pH}$ & & 6,5 & 6,6 & 6,5 & 6,5 & - & - & 6,7 & - & - & - & - & 6,9 \\
\hline İLETKENLİK & $\mu \mathrm{S} / \mathrm{cm}$ & 94,2 & 94,2 & 95,8 & 97,7 & - & - & 95,8 & - & - & - & - & 101 \\
\hline AMONYUM & $\mathrm{mg} / \mathrm{L}$ & 0 & 0 & 0 & 0 & - & - & 0 & - & - & - & - & 0 \\
\hline NITRIT & $\mathrm{mg} / \mathrm{L}$ & 0 & 0 & 0 & 0 & - & - & 0 & - & - & - & - & 0 \\
\hline KLORÜR & $\mathrm{mg} / \mathrm{L}$ & 17,8 & 17,8 & 17,8 & 17,8 & - & - & 17,8 & - & - & - & - & 17,8 \\
\hline TOPLAMSERTLIK & ${ }^{0} \mathrm{~F}$ & 2,4 & 2,4 & 2,6 & 3 & - & - & 2,6 & - & - & - & - & 3 \\
\hline FLORÜR & $\mathrm{mg} / \mathrm{L}$ & 0,01 & 0,03 & 0,01 & 0 & - & - & 0,05 & - & - & - & - & 0,01 \\
\hline KALSIYUM & $\mathrm{mg} / \mathrm{L}$ & 6,4 & 6,7 & 6,7 & 6,8 & - & - & 7,1 & - & - & - & - & 7,5 \\
\hline \multicolumn{14}{|l|}{ FERAH M. } \\
\hline SERBEST KLOR & $\mathrm{mg} / \mathrm{L}$ & 0 & 0 & 0 & 0 & 0 & 0 & 0 & 0 & 0 & 0 & 0 & 0 \\
\hline $\mathrm{pH}$ & & 5,8 & 5,8 & 6 & 6 & 6,1 & 6,2 & 6,1 & 6,2 & 6,1 & 6,4 & 6,1 & 5,9 \\
\hline İLETKENLIK & $\mu \mathrm{S} / \mathrm{cm}$ & 125,5 & 126,6 & 128 & 128,2 & 127,2 & 130,5 & 131,7 & 140 & 138 & 148,1 & 138 & 130,5 \\
\hline AMONYUM & $\mathrm{mg} / \mathrm{L}$ & 0 & 0 & 0 & 0 & 0 & 0 & 0 & 0 & 0 & 0 & 0 & 0 \\
\hline NITRIT & $\mathrm{mg} / \mathrm{L}$ & 0 & 0 & 0 & 0 & 0 & 0 & 0 & 0 & 0 & 0 & 0 & 0 \\
\hline KLORÜR & $\mathrm{mg} / \mathrm{L}$ & 26,4 & 26,6 & 25,6 & 24,9 & 26,6 & 26,6 & 28,4 & 31,9 & 30,2 & 30,2 & 28,4 & 26,6 \\
\hline TOPLAM SERTLIK & ${ }^{0} \mathrm{~F}$ & 2,5 & 2,4 & 2,4 & 2,4 & 2,4 & 2,4 & 2,6 & 2,7 & 2,6 & 3 & 3 & 2,5 \\
\hline FLORÜR & $\mathrm{mg} / \mathrm{L}$ & 0,09 & 0,18 & 0,05 & 0 & 0,04 & 0,06 & 0,06 & 0,13 & 0,1 & 0,06 & 0 & 0,33 \\
\hline KALSIYUM & $\mathrm{mg} / \mathrm{L}$ & 4,7 & 4,8 & 5,5 & 5,5 & 5,2 & 5,9 & 6,4 & 6,4 & 6,4 & 7,9 & 6,8 & 5,5 \\
\hline
\end{tabular}




\begin{tabular}{|c|c|c|c|c|c|c|c|c|c|c|c|c|c|}
\hline \multicolumn{14}{|l|}{ GÖZTEPE } \\
\hline SERBEST KLOR & $\mathrm{mg} / \mathrm{L}$ & 0 & 0 & 0 & - & - & - & - & - & - & - & - & - \\
\hline $\mathrm{pH}$ & & 7,4 & 7,6 & 7,6 & - & - & - & - & - & - & - & - & - \\
\hline İLETKENLIKK & $\mu \mathrm{S} / \mathrm{cm}$ & 180 & 180,5 & 180,5 & - & - & - & - & - & - & - & - & - \\
\hline AMONYUM & $\mathrm{mg} / \mathrm{L}$ & 0 & 0 & 0 & - & - & - & - & - & - & - & - & - \\
\hline NITRIT & $\mathrm{mg} / \mathrm{L}$ & 0 & 0 & 0 & - & - & - & - & - & - & - & - & - \\
\hline KLORÜR & $\mathrm{mg} / \mathrm{L}$ & 24,5 & 24,9 & 25 & - & - & - & - & - & - & - & - & - \\
\hline TOPLAM SERTLIKK & ${ }^{0} \mathrm{~F}$ & 6 & 6,4 & 6,4 & - & - & - & - & - & - & - & - & - \\
\hline FLORÜR & $\mathrm{mg} / \mathrm{L}$ & 0 & 0 & 0 & - & - & - & - & - & - & - & - & - \\
\hline KALSIYUM & $\mathrm{mg} / \mathrm{L}$ & 20,5 & 22,2 & 22,5 & - & - & - & - & - & - & - & - & - \\
\hline \multicolumn{14}{|l|}{ HAMINNINE } \\
\hline SERBEST KLOR & $\mathrm{mg} / \mathrm{L}$ & 0 & 0 & 0 & 0 & 0 & 0 & 0 & 0 & 0 & 0 & 0,1 & 0 \\
\hline $\mathrm{pH}$ & & 6,8 & 6,9 & 6,7 & 6,7 & 6,7 & 6,6 & 6,8 & 6,8 & 6,9 & 6,8 & 6,7 & 6,6 \\
\hline İLETKENLIK & $\mu \mathrm{S} / \mathrm{cm}$ & 230 & 233 & 240 & 240 & 237 & 238 & 239 & 238 & 240 & 253 & 247 & 244 \\
\hline AMONYUM & $\mathrm{mg} / \mathrm{L}$ & 0 & 0 & 0 & 0 & 0 & 0 & 0 & 0 & 0 & 0 & 0 & 0 \\
\hline NITRIT & $\mathrm{mg} / \mathrm{L}$ & 0 & 0 & 0 & 0 & 0 & 0 & 0 & 0 & 0 & 0 & 0 & 0 \\
\hline KLORÜR & $\mathrm{mg} / \mathrm{L}$ & 45,6 & 46,2 & 45,6 & 44,4 & 44,4 & 44,4 & 42,6 & 44,4 & 44,4 & 44,4 & 46,2 & 46,2 \\
\hline TOPLAM SERTLIKK & ${ }^{0} \mathrm{~F}$ & 7 & 7,2 & 7,2 & 7 & 7,2 & 7 & 7,4 & 7,4 & 7,5 & 7,7 & 7,7 & 7,4 \\
\hline FLORÜR & $\mathrm{mg} / \mathrm{L}$ & 0,04 & 0,04 & 0,04 & 0,06 & 0,23 & 0,13 & 0,07 & 0,13 & 0,17 & 0,16 & 0,09 & 0,37 \\
\hline KALSIYUM & $\mathrm{mg} / \mathrm{L}$ & 18,6 & 17,5 & 18,3 & 18,6 & 17,5 & 17,8 & 18,3 & 18,3 & 19,1 & 20,6 & 20,2 & 19,1 \\
\hline \multicolumn{14}{|l|}{ ICÇERENKÖY } \\
\hline SERBEST KLOR & $\mathrm{mg} / \mathrm{L}$ & 0 & 0,3 & 0 & 0 & 0 & 0 & 0 & 0 & 0 & 0 & 0 & 0 \\
\hline $\mathrm{pH}$ & & 7,2 & 7,2 & 7,1 & 6,9 & 6,9 & 6,8 & 6,9 & 7,1 & 6,9 & 6,9 & 6,7 & 6,7 \\
\hline İLETKENLIK & $\mu \mathrm{S} / \mathrm{cm}$ & 150 & 159,7 & 145,6 & 93,6 & 76,9 & 78,9 & 79,1 & 88,7 & 80,5 & 85,1 & 80,6 & 79,7 \\
\hline AMONYUM & $\mathrm{mg} / \mathrm{L}$ & 0 & 0 & 0 & 0 & 0 & 0 & 0 & 0 & 0 & 0 & 0 & 0 \\
\hline NITRIT & $\mathrm{mg} / \mathrm{L}$ & 0 & 0 & 0 & 0 & 0 & 0 & 0 & 0 & 0 & 0 & 0 & 0 \\
\hline KLORÜR & $\mathrm{mg} / \mathrm{L}$ & 20,5 & 23,1 & 19,6 & 17,8 & 17,8 & 15,9 & 15,9 & 15,9 & 17,8 & 17,5 & 15,9 & 17,8 \\
\hline TOPLAM SERTLIK & ${ }^{0} \mathrm{~F}$ & 2 & 2,2 & 2,2 & 2 & 2 & 2,2 & 2,4 & 2,4 & 2,3 & 2,4 & 2,3 & 2,3 \\
\hline FLORÜR & $\mathrm{mg} / \mathrm{L}$ & 0 & 0 & 0 & 0 & 0 & 0 & 0,14 & 0,1 & 0,02 & 0,18 & 0,01 & 0,46 \\
\hline KALSIYUM & $\mathrm{mg} / \mathrm{L}$ & 15,9 & 17,5 & 11,9 & 7,9 & 5,9 & 6,4 & 6,4 & 6,4 & 6,4 & 6,4 & 5,9 & 6,4 \\
\hline \multicolumn{14}{|l|}{ KAYIŞDAĞ } \\
\hline SERBEST KLOR & $\mathrm{mg} / \mathrm{L}$ & 0 & 0 & 0 & 0 & 0,5 & 0 & 0 & 0 & 0 & 0,1 & 0 & 0,1 \\
\hline $\mathrm{pH}$ & & 6,5 & 6,4 & 6,5 & 6,5 & 6,2 & 6,2 & 6,4 & 6,4 & 6,4 & 6,6 & 6,5 & 6,7 \\
\hline İLETKENLIK & $\mu \mathrm{S} / \mathrm{cm}$ & 76 & 77 & 83,5 & 89,4 & 83,6 & 76,9 & 71,8 & 74,4 & 72,9 & 75,3 & 78 & 77 \\
\hline AMONYUM & $\mathrm{mg} / \mathrm{L}$ & 0 & 0 & 0 & 0 & 0 & 0 & 0 & 0 & 0 & 0 & 0 & 0 \\
\hline NITRIT & $\mathrm{mg} / \mathrm{L}$ & 0 & 0 & 0 & 0 & 0 & 0 & 0 & 0 & 0 & 0 & 0 & 0 \\
\hline KLORÜR & $\mathrm{mg} / \mathrm{L}$ & 15,9 & 16 & 17,8 & 17,8 & 19,5 & 15,9 & 15,9 & 15,9 & 17,8 & 17,8 & 15,9 & 17,8 \\
\hline TOPLAM SERTLIKK & ${ }^{0} \mathrm{~F}$ & 1,8 & 1,9 & 1,9 & 1,9 & 1,8 & 1,9 & 1,8 & 1,8 & 1,8 & 1,9 & 2,3 & 2,2 \\
\hline FLORÜR & $\mathrm{mg} / \mathrm{L}$ & 0 & 0 & 0 & 0 & 0 & 0,14 & 0,01 & 0,13 & 0 & 0,13 & 0,08 & 0,05 \\
\hline KALSIYUM & $\mathrm{mg} / \mathrm{L}$ & 4,8 & 5,6 & 6,4 & 7,5 & 4,8 & 5,2 & 4,8 & 4,8 & 5,2 & 4,8 & 5,6 & 5,6 \\
\hline \multicolumn{14}{|l|}{ KOZYATAĞI } \\
\hline SERBEST KLOR & $\mathrm{mg} / \mathrm{L}$ & 0 & 0,4 & 0 & 0 & 0 & 0 & 0 & - & - & 0 & 0 & 0 \\
\hline $\mathrm{pH}$ & & 7,2 & 7,4 & 7,1 & 6,9 & 7,1 & 6,9 & 7,2 & - & - & 7,1 & 6,8 & 7,1 \\
\hline İLETKENLIK & $\mu \mathrm{S} / \mathrm{cm}$ & 190,4 & 197,6 & 170,5 & 90,7 & 79,4 & 84,6 & 89,1 & - & - & 84,2 & 80,3 & 81,8 \\
\hline AMONYUM & $\mathrm{mg} / \mathrm{L}$ & 0 & 0 & 0 & 0 & 0 & 0 & 0 & - & - & 0 & 0 & 0 \\
\hline NITRIT & $\mathrm{mg} / \mathrm{L}$ & 0 & 0 & 0 & 0 & 0 & 0 & 0 & - & - & 0 & 0 & 0 \\
\hline KLORÜR & $\mathrm{mg} / \mathrm{L}$ & 21,3 & 24,9 & 19,9 & 17,8 & 17,8 & 17,7 & 17,8 & - & - & 17,8 & 15,9 & 17,8 \\
\hline TOPLAM SERTLIK & ${ }^{0} \mathrm{~F}$ & 2,6 & 2,4 & 2,4 & 2,4 & 2,2 & 2,4 & 2,4 & - & - & 2,4 & 2,4 & 2,6 \\
\hline FLORÜR & $\mathrm{mg} / \mathrm{L}$ & 0 & 0 & 0 & 0 & 0 & 0,11 & 0,09 & - & - & 0,19 & 0 & 0 \\
\hline KALSIYUM & $\mathrm{mg} / \mathrm{L}$ & 19,8 & 24,6 & 18,5 & 7,9 & 6,8 & 6,8 & 7,4 & - & - & 6,4 & 6,8 & 6,8 \\
\hline \multicolumn{14}{|l|}{ SAHRAYI CEDID } \\
\hline SERBEST KLOR & $\mathrm{mg} / \mathrm{L}$ & 0 & 0 & 0 & 0 & 0 & - & - & - & - & - & - & 0 \\
\hline $\mathrm{pH}$ & & 7,4 & 7,6 & 7,6 & 7,4 & 7,4 & - & - & - & - & - & - & 7,3 \\
\hline İLETKENLIK & $\mu \mathrm{S} / \mathrm{cm}$ & 180,5 & 185,4 & 174,6 & 96,1 & 88,2 & - & - & - & - & - & - & 107,5 \\
\hline AMONYUM & $\mathrm{mg} / \mathrm{L}$ & 0 & 0 & 0 & 0 & 0 & - & - & - & - & - & - & 0 \\
\hline NITRIT & $\mathrm{mg} / \mathrm{L}$ & 0 & 0 & 0 & 0 & 0 & - & - & - & - & - & - & 0 \\
\hline KLORÜR & $\mathrm{mg} / \mathrm{L}$ & 20,8 & 23,1 & 23,1 & 17,8 & 17,8 & - & - & - & - & - & - & 17,8 \\
\hline TOPLAM SERTLIKK & ${ }^{0} \mathrm{~F}$ & 2,2 & 2,2 & 2,4 & 2,4 & 2,8 & - & - & - & - & - & - & 3,5 \\
\hline FLORÜR & $\mathrm{mg} / \mathrm{L}$ & 0 & 0 & 0,01 & 0,01 & 0,04 & - & - & - & - & - & - & 0,02 \\
\hline KALSIYUM & $\mathrm{mg} / \mathrm{L}$ & 19,8 & 23,4 & 15,9 & 8,7 & 7,9 & - & - & - & - & - & - & 11,9 \\
\hline
\end{tabular}




\begin{tabular}{|c|c|c|c|c|c|c|c|c|c|c|c|c|c|}
\hline \multicolumn{14}{|l|}{\begin{tabular}{|l|} 
TATLISU- 1 \\
\end{tabular}} \\
\hline SERBEST KLOR & $\mathrm{mg} / \mathrm{L}$ & 0 & 0 & 0 & 0 & 0 & 0 & 0 & 0 & 0 & 0 & 0 & 0 \\
\hline $\mathrm{pH}$ & & 6,6 & 6,7 & 6,6 & 6,6 & 6,7 & 6,6 & 6,5 & 6,7 & 6,7 & 6,7 & 6,7 & 6,7 \\
\hline İLETKENLIK & $\mu \mathrm{S} / \mathrm{cm}$ & 412 & 411 & 416 & 418 & 423 & 419 & 412 & 427 & 416 & 419 & 420 & 416 \\
\hline AMONYUM & $\mathrm{mg} / \mathrm{L}$ & 0 & 0 & 0 & 0 & 0 & 0 & 0 & 0 & 0 & 0 & 0 & 0 \\
\hline NITRIT & $\mathrm{mg} / \mathrm{L}$ & 0 & 0 & 0 & 0 & 0 & 0 & 0 & 0 & 0 & 0 & 0 & 0 \\
\hline KLORÜR & $\mathrm{mg} / \mathrm{L}$ & 78,1 & 78,1 & 78,1 & 78,1 & 78,1 & 78,1 & 78,1 & 78,1 & 76,3 & 76,3 & 76,3 & 76,3 \\
\hline TOPLAM SERTLIK & ${ }^{0} \mathrm{~F}$ & 12,6 & 12,6 & 12,8 & 12,8 & 12,9 & 12,6 & 12,8 & 13 & 13 & 13 & 12,8 & 13,4 \\
\hline FLORÜR & $\mathrm{mg} / \mathrm{L}$ & 0,1 & 0,11 & 0,1 & 0 & 0,01 & 0,09 & 0,16 & 0,12 & 0,07 & 0,22 & 0,22 & 0,1 \\
\hline KALSIYUM & $\mathrm{mg} / \mathrm{L}$ & 35,7 & 36,5 & 33,7 & 32,5 & 32,5 & 32,9 & 33,3 & 33,3 & 33,3 & 33,3 & 40,5 & 35,7 \\
\hline \multicolumn{14}{|l|}{ TATLISU- 2} \\
\hline SERBEST KLOR & $\mathrm{mg} / \mathrm{L}$ & 0 & 0 & 0 & 0 & 0 & 0 & 0 & - & - & 0 & 0 & 0 \\
\hline $\mathrm{pH}$ & & 6,4 & 6,5 & 6,4 & 6,4 & 6,4 & 6,3 & 6,4 & - & - & 6,3 & 6,4 & 6,7 \\
\hline İLETKENLIKK & $\mu \mathrm{S} / \mathrm{cm}$ & 230 & 238 & 190,5 & 168,4 & 189 & 158 & 181,6 & - & - & 171,1 & 159,5 & 153,2 \\
\hline AMONYUM & $\mathrm{mg} / \mathrm{L}$ & 0 & 0 & 0 & 0 & 0 & 0 & 0 & - & - & 0 & 0 & 0 \\
\hline NITRIT & $\mathrm{mg} / \mathrm{L}$ & 0 & 0 & 0 & 0 & 0 & 0 & 0 & - & - & 0 & 0 & 0 \\
\hline KLORÜR & $\mathrm{mg} / \mathrm{L}$ & 28,4 & 30,2 & 28,4 & 28,4 & 28,4 & 26,6 & 28,4 & - & - & 26,6 & 24,9 & 24,9 \\
\hline TOPLAM SERTLIK & ${ }^{0} \mathrm{~F}$ & 4,6 & 4,8 & 5 & 5,8 & 6 & 4,6 & 5,8 & - & - & 6 & 5 & 4,8 \\
\hline FLORÜR & $\mathrm{mg} / \mathrm{L}$ & 0,1 & 0 & 0,1 & 0 & 0,12 & 0,14 & 0,1 & - & - & 0,39 & 0,34 & 0,3 \\
\hline KALSIYYUM & $\mathrm{mg} / \mathrm{L}$ & 17,5 & 19,4 & 15,9 & 12,3 & 15,1 & 11,5 & 15,1 & - & - & 15,9 & 12,7 & 13,1 \\
\hline
\end{tabular}

(-): Kaynak suyu çeşmelerinden su akmadığı için numune temin edilememiştir.

\section{Sonuçlar}

Bu çalışmanın amacı, İstanbul (Anadolu yakası) halkının içme ve kullanma suyu olarak kullandıkları kaynak suyu çeşmelerinin, bir yıllık süreçte (2014 yılı / 12 ay) fiziksel ve kimyasal kalite parametrelerinin araştırılması ve insan sağlığ 1 açısından içme suyu kalitelerinin belirlenmesidir. Halkın kullanımına sunulan kaynak suyu çeşmelerinin içme ve kullanma amaçlarına yönelik olarak kullanılabilmeleri için insan sağlığını tehdit edici unsurları barındırmamaları ve insan sağlığına uygun su kalitesine sahip olmaları gerekmektedir. Bu bağlamda içme ve kullanma sularının Dünya Sağlık Teşkilatı (WHO) [22], ABD Çevre Koruma Ajansı (EPA) [23], Avrupa Birliği (EC) [24], Türk Standartları Enstitüsü TS 266 İçme Suyu Standardı [12] ve Sağlık Bakanlığı İnsani Tüketim Amaçlı Sular Hakkındaki Yönetmelikte [25] ifade edilen özelliklere sahip olmaları gerekir. Çalışmamız neticesinde kaynak suyu numunelerimizin tamamının organoleptik özellikler açısından, TS 266 standardına [12] uygun olarak tespit edildi. Kaynak sularımız üzerine iklim etkileri değerlendirildiğinde Meteoroloji Genel Müdürlüğü verilerine göre, kaynak sularımızı temin ettiğimiz bölgelerin, 12 aylık (Ocak 2014-Aralık 2014) kuraklık durumu normal civarı, aralık ayı yağışı $58 \mathrm{~mm}$ iken, önceki yıl olağanüstü kurak bir dönemin etkisinde kalındığı görüldü. Daha önceki 24 aylık dönemin kuraklık analizine bakıldığında ise orta derecede kurak bir dönem yaşandığ 1 tespit edildi [26]. Dolay1sıyla yağışlarda gözlenen bu eksikliğin uzun zaman devam etmesi neticesinde yeryüzü ve yer altı sularında azalma durumu olan hidrolojik kuraklık etkileri de göz önünde bulunduruldu. Nitekim sıcaklıkların yükselmesi, yağışların azalması ve artan buharlaşma ile meteorolojik kuraklığın uzaması ve insan aktiviteleriyle arazi kullanımındaki değişiklikler gibi koşullar altında kaynak suyu çeşmelerimizde bazı aylarda suların azalması hatta kesilmesi gözlendi. $\mathrm{Bu}$ durumun kaynak suyu seviyeleri, pH, iletkenlik, toplam çözünmüş madde konsantrasyonları gibi kimyasal kalite parametreleri üzerinde oldukça etkili olduğu gözlendi. Kimyasal kalite parametrelerimizde ise aşağıda sıraladığımız sonuçlara ulaşıldı. Suda çözünmüş halde bulunan karbonat, bikarbonat ve karbondioksit miktarlarından etkilenen $\mathrm{pH}$ [27] ölçümlerimizin, 5,8 - 7,6 değerleri arasında değişmekte olduğu tespit edildi. S2 çeşmesinin yıl boyu yapılan tüm analizlerde, $\mathrm{S} 6$ ve S10 çeşmelerinin ise bazı aylarda $\mathrm{pH}$ değerleri Tablo 2'de belirtilen limit değerlerin altında kalmaktayken, diğer örneklerin $\mathrm{pH}$ değerlerinin ise sınırlar içinde yer aldığı görüldü. Yer altı sularının özgül elektriksel iletkenliği, bir santimetre küp suyun $25^{\circ} \mathrm{C}$ 'deki iletkenliğidir ve her $1^{\circ} \mathrm{C}$ 'lik sıcaklık artışında elektriksel iletkenlik \% 2 oranında artış göstermektedir. Suyun çözünmüş tuz içeriğine bağlı olarak da elektriksel iletkenliği artmaktadır [27]. İletkenlik suyun elektrik iletme kapasitesini göstermekte olup, başta kalsiyum ve magnezyum olmak üzere potasyum, sodyum, bikarbonatlar, klorür ve sülfatlar gibi inorganik tuzlar ve suda az miktarda çözünmüş organik maddelerden oluşmaktadır. Dolayısıyla en yüksek iletkenlik değerine sahip olan S9 çeşmesinin klorür, toplam sertlik ve kalsiyum değerleri de en 
yüksek olan kaynak suyu numunesi olduğu görüldü. Tüm kaynak sularımızın iletkenlik değerleri standartlara uygun olarak tespit edildi. İnsan ve hayvan kaynaklı organik maddelerin bozunması ile oluşan nitrat ve nitritin sudaki mevcudiyeti bakteriyel bir bulaşmayı göstermektedir. Ayrıca azot içeren sanayi atık suları ve suni gübreler de en önemli nitrat ve nitrit kaynaklarındandır. Bu bileşikleri yüksek miktarlarda bulunduran suların insanlar tarafindan uzun süre fazla seviyelerde tüketimi zehirlenmelere neden olacağından halk sağlığının korunması açısından gerekli tedbirlerin alınması gerekir [28]. Yapılan analizler sonucunda kaynak suyu numunelerimizde amonyum ve nitrit tespit edilmedi. Vücuda alınan florun en büyük kaynağı doğal içme sularında bulunan floridlerdir. Vücuda normal değerlerde (0,7-1,2 ppm; WHO) alınan flor, sağlam kemik oluşmasını hızlandırıp, dişleri çürük oluşumuna karşı korurken, doğal içme suyu ve kaynaklarında günlük optimal flor dozundan daha yüksek flor içeren coğrafi bölgelerde yaşayan kişilerde endemik florozis'e rastlanmaktadır. Bu durum halk sağlığı açısından önemli bir sorundur [29]. Kaynak sularındaki florür miktarı, toprak ve kayaların jeolojik, kimyasal ve fiziksel özelliklerine, sıcaklığa, kimyasal elementlerin hareketine, kaynağın derinliğine bağlı olarak değişiklik göstermektedir. İstanbul'un içme sularının flor düzeyi oldukça düşük olmakla beraber piyasada satılmakta olan içme sularında bu değer 0,025-1,08 arasındadır. Dolayısıyla İstanbul'un bütün ilçelerinde yaşayan çocukların içtikleri suyun flor miktarına ve diğer flor kaynaklarını ne ölçüde tükettiklerine bakılarak flor desteği yapılması gerekir [30]. Analizlerimiz sonucunda numunelerin florür seviyelerinin Tablo 2'de belirttiğimiz ulusal ve uluslar arası standartlardaki limit değerlerin altında oldukları tespit edildi. Dezenfeksiyon amacıyla suya klor uygulaması çoğunlukla elementer klor (klor gazı), sodyum hipoklorür solüsyonu (çamaşır suyu) veya katı kalsiyum hipoklorür şeklinde yapılmaktadır. Bu uygulamalar suda serbest klor oluşumuna neden olmaktadır. Klor suya kontrollü ve kolayca uygulanabilen, suda orta derecede çözünen bir maddedir. Aynı zamanda serbest ve bağlı klorun sahip oldukları bakterisit aktivitesi sıcaklıkla artış göstermektedir [31]. Klorlanmamış suyun tüketilmesi sonucu meydana gelecek olan mikrobiyolojik riskler ile klorlanma ile oluşacak yan ürünlerin tüketiminden dolayı oluşacak uzun vadeli riskler göz önünde tutulmak zorundadır. İnsani Tüketim Amaçlı Sular Hakkındaki Yönetmelikte "İçme-kullanma sularının dezenfeksiyonunda klor ve klorlu bileşikler kullanılır, uç noktada yapılacak ölçümlerde serbest klor düzeyinin 0,2-0,5 mg/L olması sağlanır. İçme-kullanma suyunda dezenfeksiyon etkinliğinin denetlenmesi amaciyla, serbest klor ölçümleri suyun mahallinde her gün yapılır." ifadesi yer almaktadır. Buna göre sadece S5, S6 ve S7 çeşmelerinde bazı aylarda serbest klor miktarı yukarıda ifade edilen sınırlar içerisinde yer aldı. Bununla birlikte tespit ettiğimiz tüm serbest klor verilerinin Tablo 2'de ifade edilen WHO, 2011 ve EPA, 2008 standartlarındaki limit değerlere uygunluk arz ettiği görüldü. Suda bulunan iki değerlikli metal katyonlar1nın (kalsiyum $\left(\mathrm{Ca}^{+2}\right)$, magnezyum $\left(\mathrm{Mg}^{+2}\right)$ ve çok az oranda stronsiyum $\left(\mathrm{Sr}^{+2}\right)$, demir $\left(\mathrm{Fe}^{+2}\right)$ ve mangan $\left.\left(\mathrm{Mn}^{+2}\right)\right)$ neden olduğu, suyun tadını bozan, bazı endüstriyel işlemlere zarar veren, sabunun köpürmesini güçleştiren su kalitesini etkileyen parametre su sertliğidir. Yani kalsiyum ve magnezyum iyonu konsantrasyonlarının toplamı toplam sertliği göstermektedir [32]. Kaynak suyu numunelerimizin toplam sertlik değerleri standartlara uygun olarak tespit edildi. Bu veriler 1şığında değerlendirdiğimizde S4 ve S9 çeşmelerine ait kaynak suları yumuşak sular, diğer çeşmelerin suları ise çok yumuşak sular sınıfına girmektedir. Suya sertlik özelliği veren en etkili iyon kalsiyum'dur [33]. Kalsiyum seviyesi 1000 $\mathrm{mg} / \mathrm{L}$ 'yi geçen suların tüketilmesi durumunda, damar sertliği ve böbrek taşlarının oluşmasına neden olduğu düşünülmektedir [8]. Kaynak sularımızın kalsiyum değerleri Türk Standartları Enstitüsü TS 266 (2005), Dünya Sağlık Teşkilatı (WHO, 2011) ve Avrupa Birliği (EC, 1998) limit değerlerinin oldukça altında tespit edildi. Sudaki klorür iyonlar1nın miktarı sağlıklı suyun göstergesidir. Çoğunlukla içme sularında klorür miktarı 30 mg/L' yi geçmez. Deniz ve kaya tuzu yataklarına yakın bölgelerdeki sularda ise klorür konsantrasyonu yüksektir [35]. Yeraltı suyunda klorür konsantrasyonlarındaki düşüş yağmura bağlıdır. Bu durum kaynak sularının izlenmesi açısından bir kriter olarak kabul edilebilir [33]. Yaptığımız analizler sonucunda kaynak suyu çeşmelerinin klorür seviyeleri ulusal ve uluslararası standartlara uygun olarak tespit edildi. Çalışmamız neticesinde elde ettiğimiz veriler su kalitesini belirleyen parametreler açısından değerlendirildiğinde, Gümüş N.E. 'nin 2012 yılında Karaman il merkezinde tatlı su çeşme sularıyla ilgili olarak yaptığı çalışmayla benzer sonuçlar tespit edildiği görüldü. Gümüş’ün yaptığı bu çalışmada Karaman il merkezindeki tatlı su çeşme sularında kimyasal kalite parametreleri açısından florür ve serbest klor miktarı düşük düzeyde saptanırken, $\mathrm{pH}$, toplam sertlik, iletkenlik, nitrit, amonyum, kalsiyum, klorür ise ulusal ve uluslararası içme suyu standartlarına uygun bulunmuştur [36]. Şekerci'nin 2012 yılında yaptığı bir çalışmada Erzurum il merkezinde tesadüfi olarak seçilen 45 çeşmeye ait su örneklerinin kimyasal analiz sonuçlarına göre ortalama $\mathrm{pH} 7,26 \pm 0,18$, klorür $30,29 \pm 10,17$, nitrit $0,12 \pm 0,16$, amonyum $0,32 \pm 0,19$, kalsiyum $105,00 \pm 27,87$, iletkenlik 456,80 $\pm 202,51 \mu \mathrm{S} / \mathrm{cm}$ olarak tespit edilmiştir. Çalışmamızdan farklı olarak Şekerci yaptığı bu çalışmada su örneklerinde nitrit ve amonyum tespit etmiştir. İletkenlik ortalaması da oldukça yüksektir [37]. Karaoğlu M.H. (2001), 
Kavaklıdere-Bozdoğan bölgesindeki kaynak sularının üzerinde yaptığı bir çalışmada bazı örneklerde amonyum, nitrit ve nitrat'a rastlamıştır. pH, iletkenlik, sertlik ve kalsiyum seviyelerini ise standartlara uygun olarak tespit etmiştir [38]. Şekerci ve Karaoğlu yaptıkları bu araştırmalar sonucunda bazı su örneklerinde amonyum ve nitrit tespit etmeleriyle yaptığımız kaynak suyu analizlerimizden farklı sonuçlar elde etmişlerdir. Yelekçi S. ve ark.'nın 2012 yılında yaptı̆̆ 1 bir çalışmada Kilis il merkezi şebeke sularından alınan doksan örneğin tümünün $\mathrm{pH}$, elektriksel iletkenlik, sertlik, amonyum azotu, nitrit bakımından standartlara (TSE, WHO, EC ve EPA) uygun olduğu, flor seviyelerinin standartların altında olduğu, birçok su örneğinde klor seviyelerinin bazı standartlardan yüksek olduğu tespit edilmiştir [39]. Yiğit (2002) tarafından İstanbul İli Arnavutköy Beldesi civarında yapılan bir çalışmada 14 farklı kaynak/köy çeşmesinden akan suların 3 köy çeşmesinde fiziksel, kimyasal ve mikrobiyolojik olarak uygun, diğer kaynak suları ve köy çeşmelerinden akan suların ise klor ve sertlik bakımından uygun olmadığı, içme suyu olarak kullanılamayacağı bildirilmiştir. Yelekçi ve Yiğit'in bu çalışmaları, araştırmamızla kıyaslandığında bazı su örneklerinin klor seviyelerindeki uygunsuzluğun, elde ettiğimiz verilerden farklılık gösterdiği görüldü [40].

Sonuç olarak, kaynak sularımızın çoğu araştırdığımız kimyasal kalite parametreleri açısından ulusal ve uluslararas1 standartlarda belirtilen limit seviyelere uygun olarak tespit edildi. Analizlerimiz sonucunda kaynak sularımızın $\%$ 27,4'ünün $\mathrm{pH}$ değeri ulusal ve uluslararası standartlara, \% 96,8'inin serbest klor değeri ise sadece İnsani Tüketim Amaçlı Sular Hakkındaki Yönetmeliğe aykırı olarak tespit edildi. Halkın kullanımına sunulan bu kaynak suyu çeşmelerinin su kalitesi açısından sağlığı tehdit edici nitelikleri taşıması önemli sorunlara neden olacaktır. Dolayısıyla kaynak suyu çeşmeleri düzenli aralıklarla denetlenmeli ve sağlığı tehdit edici özellikler gösterdiği takdirde bu durum giderilene kadar halkın kullanımına sunulmamalıdır.

\section{Kaynaklar}

[1] WWAP (World Water Assessment Programme) (2003). United Nations World Water Development Report 3: Water for people, water for life. UNESCO Publishing/ Earthscan. Paris, London.

[2] FAO (Food and Agriculture Organisation) AQUASTAT, http://www.fao.org/nr/water/aquastat/main/index.stm, (Mart 2015).

[3] UNESCO (2000). Water Use in the World: Present Situation/ Future Needs, http://webworld.unesco.org/water/ihp/publications/waterway/webpc/pag16.html, (Mart 2015).
[4] FAO (Food and Agricultural Organization) (2007). "Coping With Water Scarty Challenge of The Twenty Centur World Water Day". http://www.fao.org/nr/water/docs/escarcity.pdf, (Mayis 2015).

[5] WWAP (World Water Assessment Programme) (2012). The United Nations World Water Development Report 4: Managing Water under Uncertainty and Risk. Paris, UNESCO.

[6] DPT (Devlet Planlama Teşkilatı) (2007). "Toprak ve Su Kaynaklarının Kullanımı ve Yönetimi Özel İhtisas Komisyonu Raporu”, Dokuzuncu Beş Yıllık Kalkınma Planı, Ankara, Türkiye.

[7] Akın, M. ve Akın, G. (2007). Suyun Önemi, Türkiye'de Su Potansiyeli, Su Havzaları ve Su Kirliliği. Ankara Üniversitesi Dil ve Tarih-Coğrafya Fakültesi Dergisi, 47(2), 105-118.

[8] Varol, S., Davraz, A. ve Varol, E. (2008). Yeraltı suyu Kimyası ve Sağlığa Etkisinin Tıbbi Jeoloji Açısından Değerlendirilmesi. TAF Preventive Medicine Bulletin, 7(4), 351-356.

[9] TS EN ISO 5667-1 (2008). ICS 13.060.45, Su Kalitesi-Numune Alma-Bölüm 1: Numune Alma Programlarının ve Numune Alma Tekniklerinin Tasarımına Dair Kllavuz. Türk Standartlar Enstitüsü, Ankara, Türkiye.

[10] TS EN ISO 5667-3 (2013). ICS 13.060.45, Su Kalitesi-Numune Alma-Bölüm 3: Su Numunelerinin Muhafaza, Taşıma ve Depolanması için Kılavuz. Türk Standartlar Enstitüsü, Ankara, Türkiye.

[11] TS ISO 5667-5 (2008). ICS 13.060.20; 13.060.45, Su Kalitesi-Numune Alma-Bölüm 5: Arıtma Tesisleri ve Boru Şebekeli Dağıtım Sistemlerindeki İçme Suyundan Numune Alma Kıla$v u z u$. Türk Standartlar Enstitüsü, Ankara, Türkiye.

[12] TS 266 (2005). ICS 13.060.20, Sular-İnsani Tüketim Amaçl Sular. Türk Standartlar Enstitüsü, Ankara, Türkiye.

[13] Hach DR/2500 Spectrophotometer Procedure Manual (2003). Method 8038, Nessler Method, Hach Company, USA.

[14] Hach DR/2500 Spectrophotometer Procedure Manual (2003). Method 8507, Diazotization Method LR, Hach Company, USA.

[15] Hach DR/2500 Spectrophotometer Procedure Manual (2003). Method 8029, SPADNS Method, Hach Company, USA.

[16] TS 8196 (1990). ICS 13.060.01;13.060.50, Su Kalitesi - Kalsiyum Tayini Edta Titrimetrik Metot. Türk Standartlar Enstitüsü Ankara, Türkiye.

[17] TS 4164 ISO 9297 (1998). ICS 13.060.01, Su Kalitesi-Klorür Tayini-Kromat Indikatörü Yanında Gümüş Nitrat Ille Titrasyon (Mohr Metodu). Türk Standartlar Enstitüsü Ankara, Türkiye.

[18] Standard Methods For The Examination of Water and Wastewater (2012). 22. Bask1, Argentometric Method (4500- $\mathrm{Cl}^{-}$ B ), American Public Health Association/American Water Works Association/Water Environment Federation, Washington DC, USA.

[19] Lovibond 2000 Comparator, DPD Chlorine Method 3. (2009). The Tintometer Limited, Lovibond House, Amesbury, England. 
[20] TS EN ISO 10523 (2013). Su Kalitesi- pH Tayini. Türk Standartlar Enstitüsü Ankara, Türkiye.

[21] Standard Methods For The Examination of Water and Wastewater (2012). 22. bask1, 2510-B, American Public Health Association/American Water Works Association/Water Environment Federation, Washington DC, USA.

[22] Guidelines for drinking-water quality (2011). 4. bask1, ISBN 978924154815 1, World Health Organization, Geneva, Switzerland.

[23] U.S. Environmental Protection Agency (2008). Drinking water contaminants. U.S. EPA, Office of Water. http://water.epa. gov/drink/contaminants/\#Byproducts, (Ocak 2015).

[24] Official Journal of the European Communities EC (1998). Directive 98/83/EC on the quality of water intended for human consumption. The European Parliament and The Counc1l of The European Union, http://eurlex.europa.eu/LexUriServ/ LexUriServ.do?uri=OJ:L:1998:330:0032:0054:EN:PDF, (Ocak, 2015).

[25] İnsani Tüketim Amaçlı Sular Hakkındaki Yönetmelik (2013). Resmi Gazete, Mart 7. sayı :28580, Sağlık Bakanlığı, Ankara, Türkiye.

[26] T.C. Orman ve Su İşleri Bakanlığı Meteoroloji Genel Müdürlüğü, Kuraklık İzleme Sistemi 2.1, www.mgm.gov.tr, http://212.175.180.197/bitkidon/grafik5.aspx?ist=17610, (Ocak 2015).

[27] Dönderici, Z.S., Dönderici, A. ve Başarı, F. (2010). Kaynak sularının fiziksel ve kimyasal kaliteleri üzerine bir araştırma. Türk Hijyen ve Deneysel Biyoloji Dergisi, 67(4), 167-172.

[28] Ağaoğlu, S., Alişarlı, M., Alemdar, S. ve Dede, S. (2007). Van Bölgesi İçme ve Kullanma Sularında Nitrat ve Nitrit Düzeylerinin Araştırılması. Yüzüncü Yıl Üniversitesi Veteriner Fakültesi Dergisi, 18(2), 17-24.

[29] Varol, E. ve Varol, S. (2010). Çevresel bir hastalık olarak florozis ve insan sağlığı üzerine etkisi. TAF Preventive Medicine Bulletin, 9(3), 233-238.
[30] Avc1, B., Uğur Baysal, S. ve Gökçay, G. (2009). Çocuklarda Flor Kullanımının Yarar ve Zararlarının Değerlendirilmesi. Istanbul Tıp Fakültesi Çocuk Sağlı̆̆l ve Hastalıkları Anabilim Dall, Çocuk Dergisi 9(1), 8-15.

[31] Oğur, R., Tekbaş, Ö.F. ve Hasde, M. (2004). Klorlama Rehberi (İçme Kullanma Sularının Klorlanması). Gülhane Askeri Tıp Akademisi, Halk Sağlığı Anabilim Dalı, Ankara, Türkiye, s. 19-28.

[32] Boysan, F. ve Şengörür, B. (2009). Su Sertliğinin İnsan Sağlığ İçin Önemi. Sakarya Üniversitesi Fen Bilimleri Dergisi, 13(1), 7-10.

[33] Çağatay, G. (1997). Su Kalitesi. Çevre Sağlığı Temel Kaynak Dizisi No:43, 1.bask1, Türkiye Cumhuriyeti Sağlık Bakanlığı Sağlık Projesi Genel Koordinatörlüğü, Temel Sağlık Hizmetleri Genel Müdürlüğü, Ankara, Türkiye, s. 56-80.

[34] Alaş, A. ve Çil, O.H.Ş. (2002). Aksaray İline İçme Suyu Sağlayan Bazı Kaynaklarda Su Kalite Paremetrelerinin İncelenmesi. Ekoloji Çevre Dergisi, 11(42), 40-44.

[35] Gümüş, N.E. (2012). Karaman ili tatlı su çeşme sularının kimyasal ve bakteriyolojik yönden incelenmesi. Yüksek Lisans Tezi, Karamanoğlu Mehmetbey Üniversitesi, Türkiye, s. 49-52.

[36] Şekerci, P. (2012). Erzurum ili çeşme sularının mikrobiyolojik, fiziksel, kimyasal analizi ve izole edilen Escherichia coli suşlarının moleküler tiplendirilmesi. Yüksek Lisans Tezi, Atatürk Üniversitesi, Erzurum, Türkiye, s. 74-75.

[37] Karaoğlu, M.H. (2001). Kavaklıdere-Bozdoğan Bölgesindeki Kaynak Sularının Kimyasal İncelenmesi. Yüksek Lisans Tezi, Muğla Üniversitesi, Türkiye, s. 46-47.

[38] Yelekçi, S., Acemioğlu, B. Ve Avc1, H. (2012). Kilis İl Merkezi İçme sularının Kullanılabilirliğinin Araştırılması. BIBAD, Biyoloji Bilimleri Araştırma Dergisi, 5(2), 77-81.

[39] Yiğit, R. (2002). İstanbul İli Gaziosmanpaşa İlçesi Arnavutköy Beldesi Civarındaki Kaynak Sularının Fiziksel, Kimyasal ve Mikrobiyolojik Özelliklerinin Araştırılması. Yüksek Lisans Tezi, Trakya Üniversitesi, Türkiye, s. 1-47. 